\title{
PATIENT SAFETY CLIMATE AT A PRIVATE HOSPITAL ${ }^{1}$
}

\author{
Maria Helena Barbosa², Daniela Rosa Floriano3, Karoline Faria de Oliveira4, Kleiton Gonçalves do Nascimento ${ }^{5}$, \\ Lúcia Aparecida Ferreira ${ }^{6}$
}

${ }^{1}$ Research funded by the Fundação de Amparo à Pesquisa do Estado de Minas Gerais (FAPEMIG).

${ }^{2}$ Ph.D. in Adult Health Nursing. Professor, Undergraduate Nursing Program and Programa de Pós-Graduação em Atenção à Saúde, Universidade Federal do Triângulo Mineiro (UFTM). Uberaba, Minas Gerais, Brazil. E-mail: mhelena331@hotmail.com

${ }^{3}$ Undergraduate Student in Nursing, UFTM. Uberaba, Minas Gerais, Brazil. E-mail: danielarosa10183@hotmail.com

${ }^{4}$ Ph.D. student, Programa de Pós-Graduação em Atenção à Saúde, UFTM. Uberaba, Minas Gerais, Brazil. E-mail: karol_fmtm2005@ yahoo.com.br

${ }^{5}$ Master's student, Programa de Pós-Graduação em Atenção à Saúde, UFTM. Uberaba, Minas Gerais, Brazil. E-mail: kleiton_uniube@ yahoo.com.br

${ }^{6}$ Ph.D. in Nursing. Professor, Undergraduate Nursing Program UFTM. Uberaba, Minas Gerais, Brazil. E-mail: lap2ferreira@yahoo. com.br

\begin{abstract}
Evaluate the patient safety climate from the perspective of the health team members at a medium-sized private hospital in a city in the state of Minas Gerais, Brazil and check for relations between the sociodemographic variables and the safety climate scores. This is a descriptive, exploratory and correlational study, conducted with 123 health professionals, with approval from the Research Ethics Committee. Data were collected using the Safety Attitudes Questionnaire. For analysis, we used Student's t-test, analysis of variance and Spearman's correlation $(\alpha=0.05)$. The general score on the instrument was 67.50 . The best domain score was found for job satisfaction (82.79) and the lowest for perceived management (58.90) and working conditions (59.58). No differences were found between the sexes, education level, presence of other employment or professional activities. The safety climate scores observed were lower than the scores recommended in the literature.
\end{abstract}

DESCRIPTORS: Patient safety. Safety management. Health personnel.

\section{CLIMA DE SEGURANÇA DO PACIENTE EM UM HOSPITAL PRIVADO}

RESUMO: Avaliar o clima de segurança do paciente na perspectiva dos profissionais da equipe de saúde em hospital privado de médio porte de um município de Minas Gerais e verificar se há relação entre as variáveis sociodemográficas e a pontuação de clima de segurança. Estudo descritivo, exploratório, correlacional, realizado com 123 profissionais da saúde, aprovado pelo Comitê de Ética em Pesquisa. Os dados foram coletados utilizando-se o Questionário de Atitudes de Segurança. Para análises, foram utilizados os testes $t$ de Student, análise de variância e correlação de Sperman $(\alpha=0,05)$. A pontuação geral do instrumento foi 67,50 . O domínio com melhor pontuação foi o de satisfação no trabalho $(82,79)$ e os domínios com menores pontos foram percepção da gerência $(58,90)$ e condições de trabalho $(59,58)$. Não houve diferenças entre os sexos, nível de escolaridade, presença de outro vínculo empregatício ou atuação profissional. Pontuações de clima de segurança estiveram abaixo do recomendado pela literatura.

DESCRITORES: Segurança do paciente. Gerenciamento de segurança. Pessoal de saúde.

\section{CLIMA DE SEGURIDAD DEL PACIENTE EN UN HOSPITAL PRIVADO}

RESUMEN Evaluar el ambiente de seguridad del paciente en la perspectiva de los profesionales del equipo de salud en un hospital privado en una ciudad del Estado de Minas Gerais. Estudio descriptivo, exploratorio y correlacional, realizado con 123 profesionales de salud, aprobado por el Comité de Ética en Investigación. Los datos se recolectaron utilizando el Safety Attitudes Questionnaire. En los análisis se utilizaron los tests $t$ de Student, análisis de la varianza y correlación de Sperman ( $\alpha=0,05)$. La puntuación general del instrumento fue de 67,50 . El dominio con mejor puntuación fue el de satisfacción en el trabajo $(82,79)$ y los dominios con menores puntajes fueron el de percepción de la gerencia $(58,90)$ y condiciones de trabajo $(59,58)$. No hubo diferencias entre los sexos, nivel de estudios, presencia de otro vínculo laboral o actuación profesional. Se han observado puntuaciones de clima de seguridad con valores por debajo de lo recomendado por la literatura.

DESCRIPTORES: Seguridad del paciente. Gestión de la seguridad. Personal de salud. 


\section{INTRODUCTION}

Patient safety has become a priority issue in health, with ongoing debates around the globe. Institutional organizations increasingly acknowledge the importance of offering total quality services, reducing unnecessary risk and damages with a view to achieving patient satisfaction and safety. ${ }^{1}$ Health institutions are more and more aware of the importance of safety climate assessments, considering that evaluating the quality of patient care is fundamental. ${ }^{2}$

The safety climate is defined as the perceptions shared between the management and workers with regard to the safety policies, procedures and practices. In short, the safety climate reflects the workers' perception on the true value of safety in an organization, as a factor that contributes to the reduction of accidental injuries. ${ }^{3}$

Measuring an institution's safety climate permits the identification of strong and weak points in the employees' behavior, and also of the most affected areas, with a view to organizing and programming interventions. ${ }^{4}$

Thus, knowing the organizational and professional factors that can influence the patient safety in health institutions is fundamental to support the implementation of interventions that can contribute to the safety climate in these institutions, besides guaranteeing the quality of care.

The objective in this research was to assess the patient safety climate from the perspective of the health team professionals at a medium-sized private hospital in a city in the State of Minas Gerais (Brazil) and to verify whether the sociodemographic variables are related with the safety climate score.

\section{METHOD}

A descriptive and exploratory correlation study was undertaken with a quantitative approach of the data.

The study was developed in the city of Uberaba-MG, whose infrastructure includes four hospitals classified as private. Only one of these accepted to participate in the study.

All nursing professionals (baccalaureate nurses, nursing technicians and auxiliary nurses), physicians (on duty and responsible for the medical and surgical teams), social workers, nutritionists, psychologists, physiotherapists, occupational thera- pists, pharmacists and pharmacy and image service technicians working in patient care at the hospital wards where the study was undertaken were invited to take part in the data collection.

Having worked at the hospital for at least one month and working at least 20 hours per week were considered as inclusion criteria. Professionals on medical leave, absent from work due to other reasons or who did not answer the questionnaire after three approach attempts were excluded from the study.

Among the 233 professionals who complied with the inclusion criteria, 25 (10.73\%) did not accept to answer the questionnaire and 85 (36.48\%) did not return the questionnaire after three approaches. Consequently, $123(52.79 \%)$ professionals answered the questionnaire. The data were collected in 2014 during three months.

The professionals were contacted at work and received clearance from their immediate head to participate. After clarifying the research objectives, ethical consent forms were collected. Next, two questionnaires were provided for the participant to complete, using the Safety Attitudes Questionnaire (SAQ), validated for Brazilian Portuguese, ${ }^{2}$ as well as a questionnaire with sociodemographic and professional variables (sex, professional category, length of experience in the specialty, work unit, main and professional activity, length of experience and work at the institution, education level and presence of other employment contract).

The SAQ was used with the authorization of the author responsible for the validation of the tool.

The questionnaire contains 41 items, 36 of which correspond to six domains: 1) Teamwork Climate (quality of relationship and cooperation among team members); 2) Safety Climate (professionals' perception of the organizational commitment to patient safety); 3) Job Satisfaction (positive view of the workplace); 4) Stress Perception (recognition of the extent to which the stressors can influence the work practice); 5) Perceptions of Management (approval of management actions at the service where the professional works or at the hospital) and; 6) Working Conditions (quality of work environment). ${ }^{5}$ At the SAQ, five items exist that do not belong to any domain, which are interpreted separately.

Each item is answered on a five-point Likert scale: 'disagree strongly', 'disagree slightly', 'neutral', 'agree slightly', 'agree strongly' and 'not ap- 
plicable'. The final score ranges between zero and 100, the former indicating the worst perceived safety climate and 100 the best. According to the authors of the original scale, positive scores are considered as $\leq 75 .{ }^{6}$ As a leveling criterion to interpret the data in this study, the score suggested by the creators of the tool was used, considering that these data have not been tested in Brazil.

The data were included in an electronic worksheet in Excel ${ }^{\circledR}$ for Windows ${ }^{\circledR}$, validated through double data entry and exported to the Statistical Package for the Social Sciences (SPSS), version 19.0 for Windows ${ }^{\circledR}$, for processing and analysis.

The qualitative variables were analyzed using descriptive statistics with absolute and percentage frequencies. For the quantitative variables, descriptive central trend (mean) and dispersion (standard deviation, minimum and maximum) measures were used.

For scoring purposes per domain, the item scores in each were added up and the result was divided by the number of items corresponding to each domain, based on the formula $(m-1) \times 25$, in which $m$ is the average number of items in the domain, ranging in the interval [0-100].

Spearman's correlation test was applied to the ordinal variables (time since graduation, length of experience in the specialty and length of experience at the institution) and the safety climate scores. The results of these correlations were presented descriptively instead of in tables. To subject the influence of the categorical variables on the safety scores to bivariate analysis, Student's t-test (dichotomous categorical) and variance (ANOVA) analysis for three or more categories were applied. Associations were considered statistically significant when $\mathrm{p} \leq 0.05$.

This study is part of the research project entitled The patient safety culture at hospitals in a region of Minas Gerais, with funding from the Fundação de Amparo à Pesquisa do Estado de Minas Gerais (FAPEMIG). Approval was obtained from the Etichal Research Committee involving Human Beings at Universidade Federal do Triângulo Mineiro (CEP-UFTM), opinion N. 2.306 on April 25 $5^{\text {th }}$ 2012, in compliance with Ministry of Health Resolution 196/96 on research involving human beings. ${ }^{7}$

\section{RESULTS}

In the population of 233 subjects, data were collected from $123(52.79 \%)$ professionals, respecting the criteria described in the method. Among these professionals, 14 (11.38\%) had already answered the same questionnaire at another institution. These subjects were reassessed, as some of the tool's characteristics are peculiar to the reality of each hospital.

As regards the number of institutional bonds, $66(53.66 \%)$ had another employment bond. Most professionals $(97 ; 78.86 \%)$ were female. In addition, the majority worked with adult patients (61; $49.59 \%$ ). The professionals from the nutrition, occupational therapy, social service, speech therapy and radiology services $(55 ; 44.71 \%)$ worked with adult and pediatric patients. Only seven professionals $(5.69 \%)$ worked with children.

The professional category that most participated were the nursing technicians with 84 (68.29\%) participants, followed by the nurses with $26(21.14 \%)$ and the auxiliary nurses with five $(4.07 \%)$ (Table 1$)$.

Table 1 - Distribution of professional category according to study participants and percentage of adhesion to the study. Uberaba-MG, 2014. (N=123)

\begin{tabular}{lcc}
\hline Professionals & N & $\%$ \\
\hline Baccalaureate nurse & 26 & 21.14 \\
Auxiliary nurse & 5 & 4.07 \\
Nursing technician & 84 & 68.29 \\
Psychologist & 1 & 0.81 \\
Physiotherapy & 2 & 1.63 \\
Social worker & 1 & 0.81 \\
Nutritionist & 2 & 1.63 \\
Speech therapist & 1 & 0.81 \\
X-ray technician & 1 & 0.81 \\
\hline
\end{tabular}

Concerning the activity sector, most professionals worked in the medical clinical area (44; $35.77 \%)$, followed by the adult intensive care unit $(23 ; 18.70 \%)$ and the emergency care service $(22$; $17.89 \%)$. Only one professional participated from the hospital infection control, radiology, ombudsman and human resources sectors, totaling $0.8 \%$ each.

The mean length of experience in the specialty area was 3.64 (standard deviation $\mathrm{SD} \pm 1.6$ ) years. On average, the professionals had $3.67(\mathrm{SD} \pm 1.66)$ years of experience at the institution and an average time since graduation of $4.67(\mathrm{SD} \pm 1.16)$ years (Table 2). 
Table 2 - Distribution of length of experience in the specialty, time since graduation and length of experience of research participants. Uberaba-MG, Brazil, 2014. $(n=123)$

\begin{tabular}{lccc}
\hline Length & $\begin{array}{c}\text { In specialty } \\
\mathbf{N}(\%)\end{array}$ & $\begin{array}{c}\text { Graduation } \\
\mathbf{N}(\%)\end{array}$ & $\begin{array}{c}\text { Experience } \\
\mathbf{N}(\%)\end{array}$ \\
\hline Less than 6 months & $12(9.76)$ & 0 & $13(10.57)$ \\
6 to 11 months & $19(15.45)$ & $3(2.44)$ & $19(15.45)$ \\
1 to 2 years & $28(22.76)$ & $16(13.01)$ & $31(25.20)$ \\
3 to 4 years & $28(22.76)$ & $35(28.46)$ & $16(13.01)$ \\
5 to 10 years & $21(17.07)$ & $42(34.15)$ & $27(21.95)$ \\
11 to 20 years & $8(6.50)$ & $19(15.45)$ & $11(8.94)$ \\
21 years or more & $7(5.69)$ & $8(6.50)$ & $6(4.88)$ \\
\hline
\end{tabular}

The mean general score was $67.50(\mathrm{SD} \pm 12.82)$, ranging between 37.20 and 94.38 .

In the analysis of the domain scores, as demonstrated in table 3, the domain with the highest score was number 3, related to job satisfaction, with an average score of $82.79(\mathrm{SD} \pm 18.09)$ points, evidencing that most professionals were satisfied and had a trusting and positive view on the work environment.

The lowest scores were found for domain 5 , related to the perceptions of the service and hospital management, with an average score of $58.90(\mathrm{SD} \pm 18.92)$, and domain 6, which assessed the job conditions, with an average score of 59.58 (SD \pm 27.76$)$ (Table 3).

Table 3 - Distribution of univariate analysis of domain scores. Uberaba-MG, Brazil, 2014

\begin{tabular}{lcccccc}
\hline \multicolumn{1}{c}{ Statistics } & $\begin{array}{c}\text { Teamwork } \\
\text { climate }\end{array}$ & $\begin{array}{c}\text { Safety } \\
\text { climate }\end{array}$ & $\begin{array}{c}\text { Job satisfac- } \\
\text { tion }\end{array}$ & $\begin{array}{c}\text { Stress recog- } \\
\text { nition }\end{array}$ & $\begin{array}{c}\text { Perceptions of } \\
\text { management }\end{array}$ & $\begin{array}{c}\text { Working } \\
\text { conditions }\end{array}$ \\
\hline Mean & 63.66 & 69.03 & 82.79 & 65.32 & 58.90 & 59.58 \\
Standard Deviation & 13.38 & 16.69 & 18.09 & 28.31 & 18.92 & 27.76 \\
Minimum & 28.57 & 25.00 & 8.33 & - & 21.43 & - \\
Maximum & 85.71 & 100 & 100 & 100 & 100 & 100 \\
\hline
\end{tabular}

In table 4 , the response frequency for items $14,33,34,35$ and 36 is displayed, which did not correspond to any of the domains according to the standards of the SAQ. As observed, most answers were concentrated in 'I strongly agree' (Table 4).

Table 4 - Response frequency of participants related to items that do no correspond to any domain. Uberaba-MG, Brazil, 2014

\begin{tabular}{|c|c|c|c|c|c|c|}
\hline Items that do not belong to any domain & $\begin{array}{l}\text { CD }^{*} \\
\mathrm{~N}(\%)\end{array}$ & $\begin{array}{c}\text { PD† } \\
\text { N (\%) }\end{array}$ & $\begin{array}{c}\text { Neutral } \\
\mathbf{N}(\%)\end{array}$ & $\begin{array}{c}\text { PA } \\
\text { N }(\%)\end{array}$ & $\begin{array}{c}\text { CA § } \\
\text { N (\%) }\end{array}$ & $\begin{array}{l}\text { NA | I } \\
\text { N (\%) }\end{array}$ \\
\hline $\begin{array}{l}\text { 14. My suggestions about safety would be acted upon if I } \\
\text { expressed them to management. }\end{array}$ & $\begin{array}{c}13 \\
(10.6)\end{array}$ & 15 (12.2) & $25(20.3)$ & $30(24.4)$ & $33(26.8)$ & $\begin{array}{c}7 \\
(5.7)\end{array}$ \\
\hline $\begin{array}{l}\text { 33. I experience good collaboration with nurses in this } \\
\text { clinical area. }\end{array}$ & $\begin{array}{c}4 \\
(3.3)\end{array}$ & 13 (10.6) & $\begin{array}{c}11 \\
(8.9)\end{array}$ & $20(16.3)$ & $72(58.5)$ & $\begin{array}{c}3 \\
(2.4)\end{array}$ \\
\hline $\begin{array}{l}\text { 34. I experience good collaboration with staff physicians } \\
\text { in this clinical area. }\end{array}$ & $\begin{array}{c}7 \\
(5.7)\end{array}$ & $14(11.4)$ & 13 (10.6) & $24(19.5)$ & $64(52.0)$ & - \\
\hline $\begin{array}{l}\text { 35. I experience good collaboration with pharmacists in } \\
\text { this clinical area. }\end{array}$ & $\begin{array}{c}13 \\
(10.6)\end{array}$ & $\begin{array}{c}12 \\
(9.8)\end{array}$ & 18 (14.6) & 23 (18.7) & $48(39.0)$ & $\begin{array}{c}9 \\
(7.3)\end{array}$ \\
\hline $\begin{array}{l}\text { 36. Communication breakdowns that lead to delays in de- } \\
\text { livery of care are common. }\end{array}$ & $\begin{array}{c}37 \\
(30.1)\end{array}$ & $29(23.6)$ & $14(11.4)$ & 23 (18.7) & $16(13.0)$ & $\begin{array}{c}4 \\
(3.3)\end{array}$ \\
\hline
\end{tabular}

${ }^{*} \mathrm{CD}$ : I strongly disagree; †PD: I slightly disagree; ¥PA: I slightly agree; § CA: I strongly agree; | | NA: Not applicable. 
Concerning the existence of correlation between the length of experience in the specialty area, a significant inverse correlation was found in the tool in general $(p=0.004 ; \rho=-0.25)$ and in domains 1 $(p=0.004 ; \rho=-0.257), 2(p=0.03 ; \rho=-0.19), 4(p=0.007$; $\rho=-0.241)$ and $6(p=0.009 ; \rho=-0.233)$.

As regards the time since graduation, a significant inverse correlation was found in domains $2(p=0.02 ; \rho=-0.20)$ and $6(p=0.009 ; \rho=-0.23)$. The length of experience at the institution also showed significant inverse correlations in the general score $(p=0.02 ; \rho=-0.21)$ and in domains $1(p=0.03 ; \rho=-0.19)$, $4(p=0.003 ; \rho=-0.26)$ and $6(p=0.03 ; \rho=-0.20)$.

Concerning the bivariate analysis, no significant differences were found between the sexes (female and male), education level (graduate degree or not) and presence of other job contract (present or not) in relation to the general or domain scores (Table 5).

Table 5 - Distribution of difference of means between sexes, graduate degree, presence of other employment bond and professional experience in relation to general and domain scores. Uberaba-MG, Brazil, 2014

\begin{tabular}{lccccccc}
\hline Variable & $\begin{array}{c}\text { General } \\
\text { score }\end{array}$ & $\begin{array}{c}\text { Teamwork } \\
\text { climate }\end{array}$ & $\begin{array}{c}\text { Safety } \\
\text { climate }\end{array}$ & $\begin{array}{c}\text { Job satisfac- } \\
\text { tion }\end{array}$ & $\begin{array}{c}\text { Stress recog- } \\
\text { nition }\end{array}$ & $\begin{array}{c}\text { Perceptions of } \\
\text { management }\end{array}$ & $\begin{array}{c}\text { Working } \\
\text { conditions }\end{array}$ \\
\hline Male sex Mean/ & 60.95 & 68.13 & 63.34 & 74.38 & 56.89 & 55.87 & 40.52 \\
SD $^{*}$ ) & $(10.95)$ & $(13.62)$ & $(16.39)$ & $(18.32)$ & $(24.14)$ & $(17.78)$ & $(29.63)$ \\
Female sex & 65.76 & 75.34 & 65.12 & 82.33 & 64.69 & 50.05 & 46.45 \\
Mean/(SD*) & $(15.40)$ & $(15.48)$ & $(30.80)$ & $(23.79)$ & $(29.91)$ & $(12.30)$ & $(19.97)$ \\
$\mathrm{p}^{\dagger}$ & 0.74 & 0.72 & 0.39 & 0.75 & 0.13 & 0.53 & 0.07 \\
Graduate degree & 65.94 & 76.23 & 70.29 & 81.15 & 62.31 & 57.78 & 40.97 \\
Mean/(SD*) & $(13.35)$ & $(15.07)$ & $(14.62)$ & $(23.65)$ & $(19.77)$ & $(21.73)$ & $(20.61)$ \\
Undergraduate & 64.34 & 72.99 & 62.79 & 80.50 & 63.33 & 48.97 & 46.71 \\
Mean/(SD*) & $(15.16)$ & $(15.43)$ & $(21.66)$ & $(22.79)$ & $(22.74)$ & $(22.15)$ & $(21.32)$ \\
$\mathrm{p}^{\dagger}$ & 0.76 & 0.93 & 0.35 & 0.17 & 0.91 & 0.69 & 0.89 \\
Other job bond & 64.38 & 73.19 & 67.33 & 78.99 & 62.15 & 56.00 & 45.33 \\
Mean/(SD*) & $(13.39)$ & $(14.58)$ & $(16.35)$ & $(15.39)$ & $(18.83)$ & $(20.89)$ & $(36.19)$ \\
No other job & 65.19 & 74.58 & 61.72 & 82.63 & 64.13 & 45.73 & 45.07 \\
Mean/(SD*) & $(16.15)$ & $(16.29)$ & $(17.83)$ & $(19.68)$ & $(19.18)$ & $(20.20)$ & $(20.36)$ \\
$\mathrm{p}^{\dagger}$ & 0.83 & 0.25 & 0.62 & 0.85 & 0.89 & 0.94 & 0.78 \\
Clinical & 65.31 & 75.36 & 65.79 & 80.50 & 63.23 & 48.76 & 47.79 \\
Mean/(SD*) & $(15.97)$ & $(15.68)$ & $(17.85)$ & $(15.50)$ & $(20.33)$ & $(22.81)$ & $(16.52)$ \\
Administrative & 65.31 & 73.49 & 49.69 & 76.43 & 66.04 & 61.95 & 22.86 \\
Mean/(SD*) & $(8.12)$ & $(11.13)$ & $(16.81)$ & $(18.64)$ & $(18.96)$ & $(10.59)$ & $(23.32)$ \\
Both & 62.79 & 68.58 & 65.49 & 82.50 & 61.62 & 56.91 & 42.67 \\
Mean/(SD*) & $(11.12)$ & $(14.48)$ & $(16.41)$ & $(12.51)$ & $(16.78)$ & $(20.78)$ & $(22.40)$ \\
$\mathrm{p}^{\ddagger}$ & 0.76 & 0.16 & 0.35 & 0.82 & 0.93 & 0.77 & 0.23 \\
\hline
\end{tabular}

*SD: Standard Deviation; ${ }^{\dagger} \mathrm{p}$ : p-value (Student's T test); ${ }^{\ddagger} \mathrm{p}$ : $\mathrm{p}$-value (Anova test)

When ANOVA was applied with regard to the professional activity (clinical, administrative or both), no significant difference was found between the scores of the groups $(p<0.05)$ (Table 5).

\section{DISCUSSION}

Among the study participants, the nursing team was predominant (93.49\%). In the literature, studies using the same tool also revealed a greater proportion of nursing professionals in their samples: $93 \%,{ }^{8} 45 \%{ }^{9}$ and $65 \% .{ }^{10}$
The proportions of staff physicians and pharmacists were smaller. The low response frequency of physicians was observed in other studies using the same tool, corresponding to $2.4 \%,{ }^{9} 7 \%^{8}$ and $6 \%{ }^{10}$ of the population for example. Nevertheless, in a study undertaken at a general and obstetric surgical center of a teaching hospital found high rates of adhesion of the staff physicians (67 physicians; $36.21 \%$ ). ${ }^{11}$ At that hospital, however, the Safe Surgery Program had already been established for three years, which may have contributed to higher adhesion rates among these professionals. 
The adhesion rate of these professionals might be lower because, although the theme involves all health professionals, it is more prevalent in the curricular matrix of nursing education courses.

Most professionals were female (78.9\%), as found in other studies originating in Taiwan $(87.2 \%),{ }^{10}$ India $(54.00 \%)^{9}$ and Sweden $(89 \%)$, among others. ${ }^{12}$ In the health sector, more than $75 \%$ of the female workforce is professionally active, with great concentration among nursing professionals. In line with these data, in Brazil, nursing, including baccalaureate nurses, nursing technicians and auxiliary nurses, represents the largest workforce at the health institutions. ${ }^{13}$

On average, the professionals in this study had been professionally active at the institution for 3.67 years and the mean experience in the specialty area was 3.64 years. In line with these data, a study undertaken at 13 general hospitals in Saudi Arabia showed that most professionals also had less than five years of experience in the specialty.$^{14}$ The length of professional experience at the institution and in the sector are important indicators of patient safety, representing the professional turnover inside the institution, which makes it impossible to maintain effective patient care and improves the interaction with respect to the standardization of regulations and routines at the sector. ${ }^{2}$

The mean general score was 67.50 , that is, inferior to the score recommended in the literature, representing a low safety climate. In the literature, studies were found that support the present data, such as 63.8 points, $^{8} 61.5$ points $^{2}$ and 41.4 points, ${ }^{10}$ for example.

In the domain analysis, the average score in the first domain, the teamwork climate, was 63.66 points (SD \pm 13.38 ), demonstrating a bad perception of the relationship quality and of the cooperation among the team members. Studies also found similar averages. ${ }^{8,10}$ This can reflect constant interpersonal problems, an uncooperative team and workers who are frustrated with their professional acknowledgement. ${ }^{8}$ Interdisciplinary team training programs, efficient communication mechanisms and continuing education on automated measures lead to a better teamwork climate. ${ }^{15-16}$

The mean score in the second domain, safety climate, was 69.03 points (SD \pm 16.69 ), below the recommended score, evidencing the incipient organizational commitment at the institution focused on patient safety. Other studies show similar data. ${ }^{8-10}$

When the health professionals do not perceive a good safety climate, this indicates that they do not see an actual dedication to patient safety at their service. ${ }^{8}$ Measures such as error reporting without punishment and reformation of administrative processes to make the workers feel at ease to discuss safety contribute to improve and maintain the safety climate at the institutions. ${ }^{17}$

The domain score in the third domain, job satisfaction, corresponded to 82.79 points, evidencing the professionals' positive perception of their work. In addition, the highest average score was found for this domain, which supports the findings of a study developed at ten American and two Swiss hospitals, with an average score of 77.6.

In an integrative review that assessed the job satisfaction in the nursing team, it was observed that satisfaction involves professional recognition, wellbeing, excellence in care and good relationships at work, which strongly influences the institution and the clients. On the other hand, the lack of socialization and complicity among the teams, the work burden, the professional discredit, the lack of material resources and the low salaries can cause dissatisfaction. ${ }^{18}$

The fourth domain, stress recognition, acknowledges the extent to which the stressors can influence the work practice, with an average score of 65.32 points. In other studies that used the SAQ, low average scores were also found for stress, ranging from 30.7 to 58.7 points, ${ }^{8,19-21}$ demonstrating that these professionals do not recognize that situations of tension and stress negatively affect their performance.

The perceptions of management correspond to the fifth domain in this study, with an average of 58.90 points. This domain is related to the approval of the management actions, at the service as well as the hospital as a whole. This item showed the worst average score in the study, demonstrating the professionals' dissatisfaction with the management actions related to safety aspects. This can reflect the fact that the professionals that the management is not concerned with the wellbeing of the patients and the institution. Lower scores were found in other studies, with averages ranging between 37 and 55 points. ${ }^{8,10,19,22-23}$

Creating an atmosphere in the work environment favors an open dialogue about errors, the provision of a non-punitive sphere and the ongoing training of the professionals are some of the main hospital and service management actions that can positively affect the patient safety. ${ }^{15-16}$

The sixth domain is focused on the working conditions through the perceived quality of the 
environment, with a mean score of 59.58. The professionals' perspective on the quality of the workplace is negative, in line with other studies, with scores ranging from 40 to 65 points. ${ }^{5,8,19,22-23}$

This may indicate shortages in the training programs, non-representative participation of the professionals in institutional decisions, demanding actions for improvements. ${ }^{8}$ Conditions like an unbalanced nurse-patient relationships and long workdays contribute to professional exhaustion and error events, as they reduce their interactions with the patients and limit the effective sue of knowledge and skills. ${ }^{24}$

\section{CONCLUSION}

From the perspective of the health team professionals at a private hospital in Uberaba-MG, the patient safety climate was considered inferior to the literature recommendations, which can entail professional attitudes not focused on safe choices or the planning of actions with gaps regarding what could cause harm to the patients.

The worst scores found include the perceptions of the service and hospital management and the working conditions, which represent fundamental tools to develop safe practice.

The sociodemographic variables did not interfere in the assessment of the safety climate score. According to the professional profile, a significant inverse correlation was found in the overall tool and in most domains with the length of experience in the specialty. A significant inverse correlation was also found in two domains with the time since graduation, and an inverse correlation between the length of experience and the general score and three domain scores.

The assessment of the institutional safety climate permits targeting actions to reduce the factors that contribute to errors, thus promoting higher quality care and furthering the safety of professionals and patients.

\section{REFERENCES}

1. Charles V. Segurança do paciente: orientações para evitar os eventos adversos. Porto Alegre (RS): Yendis; 2010.

2. Carvalho REFL, Cassiani SHB. Questionário Atitudes de Segurança: adaptação transcultural do Safety Attitudes Questionnaire - Short Form 2006 para o Brasil. Rev Latino-Am Enfermagem [Internet]. 2012 [cited 2015 Aug 5]; 20(3):. Available from: http:// www.scielo.br/pdf/rlae/v20n3/pt_a20v20n3.pdf
3. The Nordic Council of Ministers. National Research Centre for the Working Environment Publications Questionnaires NOSACQ-50 - Safety Climate Questionnaire [Internet]. [cited 2014 Dec 09]. Available from: http://www.arbejdsmiljoforskning.dk/en/ publikationer/spoergeskemaer/nosacq-50 2014

4. Reis CT, Laguardia J, Martins M. Translation and cross-cultural adaptation of the Brazilian version of the Hospital Survey on Patient Safety Culture: initial stage. Cad Saúde Pública. 2012 Jan-Nov; 28(1):2199210.

5. Rigobello MCG, Carvalho REFL, Cassiani SHB, Galon T, Capucho HC, Deus NN. Clima de segurança do paciente: percepção dos profissionais de enfermagem. Acta Paul Enferm [Internet]. 2012 [cited 2015 Aug 5]; 25(5):728-35. Available from: http://www.scielo.br/ pdf/ape/v25n5/13.pdf

6. SextonJB, Thomas EJ. The safety attitudes questionnaire (SAQ): guidelines for administration. Huston (US): The University of Texas Center of Excellence for Patient Safety Research and Practice; 2003.

7. Ministério da Saúde (BR). Conselho Nacional de Saúde. Resolução 196, de 10 de outubro de 1996. Brasília (DF): Diário Oficial da União: 1996. Seção 1.

8. Schwendimann R, Zimmermann N, Küng K, Ausserhofer D, Sexton B. Variation in safety culture dimensions within and between US and Swiss Hospital Units: an exploratory study. BMJ Qual Saf. 2013 Jan; 22(1):32-41.

9. Patel, $\mathrm{S}, \mathrm{Wu} \mathrm{AW}$. Safety Culture in Indian Hospitals: A Cultural Adaptation of the Safety Attitudes Questionnaire. J Patient Saf. 2016 Jun; 12(2):75-81.

10. Lee WC, Wung HY, Liao HH, Lo CM, Chang FL, Wang PC, et al. Hospital safety culture in taiwan: a nation wide survey using chinese version safey attitudes questionnaire. BMC Health Serv Res. 2010 Aug 10;10:234

11. Cauduro FLFC. Avaliação da cultura de segurança em unidades cirúrgicas [dissertação]. Curitiba (PR): Universidade Federal do Paraná; 2013.

12. Göras C, Wallentin FY, Nilsson U, Ehrenberg A. Swedish translation and psychometric testing of the safety attitudes questionnaire (operating room version). BMC Health Serv Res. 2013 Mar 19; 13:104.

13. Conselho Federal de Enfermagem (CFE). Atlas da Enfermagem - Profissionais de enfermagem por sexo no Brasil [Internet]. Brasília, DF: CFE; 2011 [cited 2015 Aug 5]. Available from: http://www.cofen.gov.br/ wp-content/uploads/2012/03/pesquisaprofissionais. pdf

14. Alahmadi HA. Assessment of patient safety culture in Saudi Arabian hospitals. Qual Saf Health Care. 2010 Oct; 19(5):e17.

15. Weaver SJ, Lubomksi LH, Wilson RF, Pfoh ER, Martinez KA, Dy SM. Promoting a Culture of Safety as a Patient Safety Strategy: a systematic review. Ann Intern Med. 2013 Mar 5; 158(5 Pt 2):369-74. 
16. Fagan MJ. Techniques to improve patient safety in hospitals: what nurse administrators need to know. J Nurs Adm. 2012 Sep; 42(9):426-30.

17. Mcfadden KL, Stock GN, Gowen CR. Leadership, safety climate, and continuous quality improvement: impact on process quality and patient safety. J Nurs Adm. 2014 Oct; 44(10 Suppl):S27-37.

18. Melo MB, Barbosa MA, Souza PR. Satisfação no trabalho da equipe de enfermagem: revisão integrativa. Rev Latino-Am Enferm [Internet]. 2011 Jul.-Ago [cited 2015 Aug 6]; 19(4):[09 telas]. Available from: http:/ / www.scielo.br/pdf/rlae/v19n4/pt_26. pdf

19. Chaboyer W, Chamberlain D, Hewson-Conroy K, Grealy B, Elderkin T, Brittin M, et al. CNE Article: Safety culture in australian intensive care units: establishing a baseline for quality improvement. Am J Crit Care. 2013 Mar; 22(2):93-102.

20. Profit J, Etchegaray J, Petersen LA, Sexton JB, Hysong SJ, Mei M, et al. The safety attitudes questionnaire as a tool for bench marking safety culture in the
NICU. Arch Dis Child Fetal Neonatal Ed. 2012 Mar; 97(2):F127-32.

21. Raftopoulos V, Pavlakis A. Safety climate in 5 intensive care units: a Nationwide hospital survey using the Greek-Cypriot version of the safety attitudes questionnaire. J Crit Care. 2013 Feb; 28(1):51-61.

22. Marinho MM, Radünz V, Barbosa SFF. Assessment of safety culture by surgical unit nursing teams. Texto Contexto Enferm [Internet]. 2014 [cited 2015 Aug 6]; 23(3):581-90. Available from: http://www. scielo.br/scielo.php?script=sci_arttext\&pid=S010407072014000300581\&lng=en\&nrm=iso\&tlng=en\&O RIGINALLANG=en

23. Gutiérrez-Cía I, De Cos Pm, Juan Ay, Obón-Azuara B, Alonso-Ovies Á, Martin-Delgado Mc, et al. Percepcíon de la cultura de seguridade en los servicios de medicina intensiva españoles. Med Clínica. 2010 Jul; 135(1):37-44.

24. Atefi N, Abdullah KL, Wong LP, Mazlom R. Factors influencing registered nurses perception of their overall job satisfaction: a qualitative study. Int Nurs Rev. 2014 Sep; 61(3):352-60. 